\title{
Racial and Ethnic Disparities in Early Childhood Obesity
}

\author{
Inyang A. Isong, MD, MPH, ScD, a,b Sowmya R. Rao, PhD, ${ }^{c}$ Marie-Abèle Bind, PhD, ${ }^{d}$
}

Mauricio Avendaño, PhD, ${ }^{\mathrm{b}, \mathrm{e}}$ Ichiro Kawachi, MD, PhD, ${ }^{\mathrm{b}}$ Tracy K. Richmond, MD, MPHa

\begin{abstract}
OBJECTIVES: The prevalence of childhood obesity is significantly higher among racial and/or ethnic minority children in the United States. It is unclear to what extent well-established obesity risk factors in infancy and preschool explain these disparities. Our objective was to decompose racial and/or ethnic disparities in children's weight status according to contributing socioeconomic and behavioral risk factors.
\end{abstract}

METHODS: We used nationally representative data from 10700 children in the Early Childhood Longitudinal Study Birth Cohort who were followed from age 9 months through kindergarten entry. We assessed the contribution of socioeconomic factors and maternal, infancy, and early childhood obesity risk factors to racial and/or ethnic disparities in children's BMI $z$ scores by using Blinder-Oaxaca decomposition analyses.

RESULTS: The prevalence of risk factors varied significantly by race and/or ethnicity. African American children had the highest prevalence of risk factors, whereas Asian children had the lowest prevalence. The major contributor to the BMI $z$ score gap was the rate of infant weight gain during the first 9 months of life, which was a strong predictor of BMI $z$ score at kindergarten entry. The rate of infant weight gain accounted for between $14.9 \%$ and $70.5 \%$ of explained disparities between white children and their racial and/or ethnic minority peers. Gaps in socioeconomic status were another important contributor that explained disparities, especially those between white and Hispanic children. Early childhood risk factors, such as fruit and vegetable consumption and television viewing, played less important roles in explaining racial and/or ethnic differences in children's BMI $z$ scores.

Conclusions: Differences in rapid infant weight gain contribute substantially to racial and/or ethnic disparities in obesity during early childhood. Interventions implemented early in life to target this risk factor could help curb widening racial and/or ethnic disparities in early childhood obesity.

\begin{abstract}
aBoston Children's Hospital, Boston, Massachusetts; ${ }^{b}$ Department of Social and Behavioral Sciences, Harvard T.H Chan School of Public Health and dDepartment of Statistics, Faculty of Arts and Sciences, Harvard University, Cambridge, Massachusetts; 'Department of Surgery, Boston University, Boston, Massachusetts; and ${ }^{e}$ Department of Social Science, Health and Medicine, King's College London, London, United Kingdom

Drs Rao and Bind helped with data analysis, interpretation of the results, and revision of the manuscript; Drs Avendaño, Kawachi, and Richmond helped with the concept and design, data interpretation, and drafting and revision of the manuscript; Dr Isong helped with the concept, design, data analysis, interpretation of the data, and drafting and revision of the manuscript; and all authors approved the final manuscript as submitted and agree to be accountable for all aspects of the work
\end{abstract}

DOI: https://doi.org/10.1542/peds.2017-0865

Accepted for publication 0ct 2, 2017
WHAT'S KNOWN ON THIS SUBJECT: Childhood obesity is a significant public health challenge.Early childhood obesity prevalence is disproportionately higher among racial and/or ethnic minority children compared with their white peers. It is unclear which specific obesity risk factors underlie and explain these disparities.

WHAT THIS STUDY ADDS: Differences in rapid infant weight gain contribute substantially to racial and/or ethnic disparities in obesity during early childhood. 
The prevalence of childhood obesity is significantly higher among racial and/or ethnic minority children in the United States compared with white children. ${ }^{1}$ Obesity is more prevalent among American Indian and/or Native Alaskan (31.2\%), non-Hispanic black (20.8\%), and Hispanic (22.0\%) children compared with their white $(15.9 \%)$ and Asian (12.8\%) peers. ${ }^{1}$ Obesity has been linked to genetic, epigenetic, biological, social, and environmental determinants and risk factors ${ }^{2,3}$ and is associated with multiple consequences. ${ }^{4}$

Childhood obesity is associated with various behavioral factors, including maternal smoking during pregnancy, ${ }^{5}$ breastfeeding, ${ }^{6}$ television viewing, and physical inactivity. ${ }^{7}$ Some of these risk factors vary by race and/ or ethnicity and socioeconomic status (SES), ${ }^{8,9}$ leading some researchers to hypothesize that differences in the prevalence of these factors across racial and/or ethnic groups could explain observed disparities. ${ }^{10}$ Differences in socioeconomic measures across racial and/or ethnic groups could also contribute to the disparities. The relationship between SES and obesity has also been shown to vary by race and/or ethnicity and sex..$^{11}$ Researchers in that study documented an inverse relationship between SES and overweight and/ or obesity among white, Asian, and Hispanic children but not among American Indian and African American children. ${ }^{11}$ Reasons for these differences are not clear, partly because data on obesity risk factors remain sparse among certain racial and/or ethnic minority groups (eg, Asian and American Indian children).

Few researchers have explored the explanation of racial and/or ethnic differences in early childhood obesity rates. ${ }^{9,10,12}$ Existing studies found that some prenatal, perinatal, and early life and childhood risk factors (eg, maternal smoking during pregnancy, breastfeeding, child care arrangements, sleep duration, television viewing, fast-food intake, and family meals) could explain a large part of BMI differences across racial and/or ethnic groups. However, some gaps in knowledge remain. Previous studies have not specified risk factors for different developmental time periods. There is a need for better understanding of the relative contribution of specific obesity risk factors to racial and/or ethnic disparities at different stages of the life course and to design effective, targeted interventions. For example, if early life factors are more influential in the development of racial and/ or ethnic disparities in obesity prevalence than later risk factors, focusing mostly on risk factors from later childhood could limit efforts to eliminate disparities. Our goal in this study was to quantify the relative contribution of socioeconomic and behavioral risk factors to racial and/or ethnic disparities in early childhood weight status by using nationally representative data. We sought to provide a clearer picture of the factors underlying racial and/or ethnic disparities in early childhood obesity and highlight the modifiable risk factors that could be prioritized and targeted in interventions.

\section{METHODS}

Data were from $\sim 10700$ US children born in 2001 and followed for 6 years in the Early Childhood Longitudinal Study Birth Cohort (ECLS-B), a stratified clustered survey designed and administered by the National Center for Education Statistics (NCES). ${ }^{13}$ A multistage, complex sampling strategy was used to draw the sample. American Indian and Native Alaskan children, Chinese, other Asian, and Pacific Islander children, twins, and low birth weight children were oversampled. Waves of data were collected when the children were aged $\sim 9$ months (wave 1 ),
2 years (wave 2), 4 years (wave 3 , preschool interview), and between 5 and 6 years (wave 4, kindergarten entry interview). We used data from 4 waves for this analysis. The study was approved by the NCES and the Harvard T.H. Chan School of Public Health institutional review board. Per NCES ECLS-B data reporting requirements, all unweighted sample sizes were rounded to the nearest 50 .

\section{Outcome Variable}

We used BMI $z$ scores from wave 4 (kindergarten entry) as our main dependent variable. A child's length or height and weight were measured by using a measure mat, stadiometer, and a digital bathroom scale, respectively. We calculated BMI $z$ scores using the Centers for Disease Control and Prevention's sex-specific BMI-for-age growth charts. ${ }^{14}$

\section{Exposure Variables}

Parents reported their children's race and/or ethnicity by choosing 1 or more options displayed on a card. On the basis of parent responses, the ECLS-B assigned children to the following racial and/or ethnic categories: Asian, Pacific Islander, American Indian, non-Hispanic white, non-Hispanic black, Hispanic, and multiracial. For this study, we assigned children to 1 of 5 racial and/or ethnic categories: any child who had at least 1 race and/ or ethnicity group reported by the parent as American Indian was categorized as American Indian. In a similar, prioritized manner, we then categorized children to African American, Hispanic, Asian, and white categories, in that order. Because of limited sample sizes and distributions, we restricted our analytic sample to the following categories: white (reference group), African American, American Indian, Hispanic, and Asian (Pacific Islander children were not included in our analyses). 


\section{Model Covariates}

Obesity Risk Factors

Obesity behavioral risk factors were collected at wave 1 or wave 3 and were grouped into 3 types: (1) maternal risk factors from wave 1 , (2) infancy risk factors from wave 1 ; and (3) early childhood risk factors from wave 3 . We chose variables from waves 1 and 3 to ensure that risk factor measurement preceded the outcome: BMI $z$ score at wave 4 . Supplemental Table 4 displays all variables, their measurement, and categories.

\section{Maternal Risk Factors (Wave 1)}

Maternal risk factors included

(1) mother's weight (kg) and (2) maternal history of smoking during pregnancy (yes or no).

\section{Infancy Risk Factors (Wave 1)}

Infancy risk factors included (1) history of breastfeeding (ever breastfed versus never breastfed), (2) age at introduction of solid foods ( $\leq 4$ months versus $>4$ months), and (3) infant weight gain based on the 9-month rate of infant weight gain (calculated as the difference in weight at the time of data collection and birth weight $[\mathrm{kg}]$ divided by age in months at the time of data collection).

\section{Early Childhood Risk Factors (Wave 3)}

Early childhood risk factors included (1) television-viewing ( $\geq 2$ hours per day of television and/or DVD viewing on weekdays and weekends versus less), (2) sugar-sweetened beverage (SSB) consumption (regular SSB drinkers [ie, drank $\geq 1$ serving of SSB per day] versus infrequent and nondrinkers [ $<1$ drink per day]), (3) fruit and vegetable consumption (adequate consumption $[\geq 1$ times per day] versus inadequate consumption [ $<1$ time per day]), (4) physical activity (child went outside to walk or play at least once per day versus less than once per day), (5) family meals (regular family meals
[ $\geq 4$ meals together per week] or not), (6) and child care arrangement (parental versus nonparental). The ECLS-B provides a composite variable to indicate the primary, nonparental child care arrangement based on where the child spent the most hours per week.

\section{Socioeconomic Factors (Wave 1)}

Socioeconomic factors included (1) household SES (a composite variable developed by the ECLS-B for children's SES at baseline data collection), and the variable was categorized into quintiles and comprised information on the mother's and father's educational attainment, occupational category and prestige score, and household income; (2) household food insecurity, which was assessed by using a series of questions obtained from the Household Food Security Scale (if parents had $\geq 3$ affirmative responses to questions, the household was categorized as food insecure [versus food secure]); and (3) neighborhood safety (unsafe versus safe on the basis of parents' perceptions of their neighborhood safety).

\section{Statistical Analysis}

We created our overall study sample by examining children's weight and height trajectories at each wave and excluding children who had implausible height values $(n=100)$, were born with low or very low birth weight (ie, birth weight <2500 g; $n=$ 3000 ), had height and weight values missing for all waves $(n=150)$, and had extreme BMI values $(z$ score $>3$ SD or $\leq-3 \mathrm{SD} ; n=100$ ). For the decomposition analyses, we excluded observations with missing values on any of the independent variables, leaving us with a sample size of $\sim 4400$. We examined differences in the distribution of all variables by race and/or ethnicity by using $\chi^{2}$ and $t$ tests ( 2 -sided $P<.05$ was considered significant). To first examine the relationship between obesity risk factors (at 1 time point) and BMI $z$ scores at kindergarten entry within each racial and/or ethnic group, we used multivariable ordinary least squares (OLS) regression models. Subsequently, to quantify the degree to which risk factors explained racial and/or ethnic disparities in children's BMI $z$ scores, we employed the BlinderOaxaca decomposition technique, ${ }^{15,16}$ which is commonly used to examine wage differentials, ${ }^{15,16}$ health disparities, ${ }^{17,18}$ and in recent years, obesity research. ${ }^{19-23}$ Briefly, the method involves estimating the regression coefficients by fitting the OLS regression for the reference category and then predicting the outcomes for the other groups by using their covariate distributions. The difference between the observed and predicted averages for the comparative group is the proportion of the disparity that is not explained by the covariates in the model. For clarification purposes, in the data supplement section, we describe the steps employed for a decomposition analysis by using an example based on OLS models comparing white and African American boys. For a more comprehensive explanation of the Blinder-Oaxaca technique, we recommend articles by Jann ${ }^{24}$ and Sen. ${ }^{19,20}$ We performed our decomposition analyses by using the "Oaxaca" command in the Stata statistical package (StataCorp, College Station, TX) with the "svy" routine to account for the ECLS-B survey weights. Sex-stratified, pairwise comparisons between white children and each racial and/or ethnic minority group were conducted. Because white children had the largest sample size, they were used as the reference category to compare with children of other races and/or ethnicities. We first categorized model covariates into 4 groups (sociodemographic, maternal, infancy, and early childhood factors), followed by detailed analyses for individual covariates 
within each risk category. Finally, by using the regression results, we computed the percent explained (PE\%), which represents the contribution to explained disparities from each covariate. ${ }^{19}$ The total $\mathrm{PE} \%$ indicates how much of the mean difference in BMI $z$ scores is accounted for by group differences in the distributions of all model covariates. All models were adjusted for child age and accounted for the complex ECLS-B design. Given the documented differences in BMI by sex, ${ }^{25}$ analyses were stratified by sex. As recommended, we estimated coefficients from a pooled regression over both comparison groups and included a group indicator as an additional covariate. ${ }^{24}$ We also conducted sensitivity analyses by fitting models that used coefficients from white children as the reference group, and the results did not differ substantively. All analyses were conducted by using statistical software (SAS version 9.3 [SAS Institute, Inc, Cary, NC] and Stata 12).

\section{RESULTS}

Overall, $51.3 \%$ of the sample were boys, $54.6 \%$ were white, $23.3 \%$ were Hispanic, $15.8 \%$ were African American, 2.9\% were American Indian, and 3.5\% were Asian (Table 1). At baseline (age $\sim 2$ years), on average, Asian children had the lowest BMI $z$ scores (0.29 [0.08 SD]), whereas American Indian children had the highest BMI $z$ scores $(0.67$ [0.15 SD]). At kindergarten entry, BMI $z$ scores were also lowest among Asian children (0.41 [0.07 SD]) and highest among American Indian children (0.98 [0.08 SD]). BMI $z$ scores by race and/or ethnicity and sex are displayed in Table 1.

In terms of socioeconomic factors, Hispanic, African American and American Indian children were more disadvantaged compared with their Asian and white peers. For example, a higher proportion of African American (56.7\%), Hispanic (51.3\%), and American Indian (50.1\%) children belonged to households earning $<\$ 25000$ per year compared with white (19.8\%) and Asian children (17.7\%). A higher percentage of African American and Hispanic children lived in households that were food insecure or in unsafe neighborhoods compared with their white and Asian peers. In addition, the obesity risk factor profile among Hispanic, African American, and American Indian children was less favorable than those of white and Asian children. African American children had the highest and Asian children the lowest prevalence of risk factors of all racial and/or ethnic groups. A higher proportion of Asian children were breastfed, watched $\leq 2$ hours of television, consumed less SSBs, and ate more fruits and vegetables compared with their peers of other racial and/or ethnic groups. Asian mothers also had the lowest prevalence of maternal smoking during pregnancy. Because the lower prevalence of obesity risk factors among Asian and white children could reflect, at least in part, their more advantaged SES compared with their peers, we also estimated the prevalence of risk factors accounting for SES, neighborhood safety, and food insecurity. In these models, African American children still had the highest prevalence of obesity risk factors, whereas the prevalence among Hispanic children was similar to those of Asian children (data available on request).

Results of multivariable regression analyses indicated that associations between BMI $z$ score and individual risk factors were generally modest and varied by sex and race and/or ethnicity (Table 2). For example, an early introduction of solid foods had a significant, positive association with BMI $z$ scores among African American and American Indian boys, whereas it was significantly associated only among American
Indian girls. Eating meals as a family was positively associated with BMI $z$ scores among Hispanic girls but negatively associated among African American girls. The magnitude of most of these associations was small. Rapid infant weight gain was the only variable that had a consistently strong, positive association with BMI $z$ score at kindergarten entry across all racial and/or ethnic groups and by sex (except among American Indian boys).The average contribution of risk factors to the explained portion of the gaps in BMI $z$ scores between white and other racial and/or ethnic boys and girls are displayed in Table 3. Among African American boys, the combined differences in risk factors explained $-0.11 \mathrm{U}$ of the $-0.18 \mathrm{U}$ gap in mean predicted BMI $z$ scores, which is $\sim 64 \%$. By contrast, the sociodemographic, maternal, infant, and early childhood risk factors included in the model collectively accounted for only $\sim 25 \%$ of racial differences between Asian and white girls. Indeed, for some racial and/or ethnic groups, a large portion of the difference in BMI $z$ scores remained unexplained. Of all the risk factor groups, infancy risk factors had the most substantial contribution to the explained portion of the model. In this group, the rate of infant weight gain played the most influential role, although this varied by race and/or ethnicity and sex. For example, differences in infant weight gain between white and African American boys accounted for $70.5 \%$ ( -0.080 of -0.113 ) of the explained gap in BMI $z$ scores between the 2 groups, whereas between white and Asian girls, it accounted for only $14.9 \%$ of the explained gap (Supplemental Table 6).

Gaps in socioeconomic factors were another important contributor to explained disparities. Within this category, household SES was the individual covariate with the highest $\mathrm{PE} \%$, with values ranging from $3.4 \%$ among white versus African 
TABLE 1 Child and Parent Socioeconomic Characteristics, Obesity Risk Factors, and BMl z Scores by Child Race and/or Ethnicity: ECLS-B

\begin{tabular}{|c|c|c|c|c|c|c|}
\hline Characteristic & Overall & $\begin{array}{l}\text { African } \\
\text { American }\end{array}$ & Hispanic & Asian & American Indian & White \\
\hline Distribution of race, $\%$ & & 15.8 & 23.3 & 3.5 & 2.9 & 54.6 \\
\hline Boys, \% & 51.3 & 53.6 & 51.8 & 53.2 & 50.4 & 50.3 \\
\hline \multicolumn{7}{|l|}{ Household income, $\$(\%)^{a}$} \\
\hline$<25000$ & 33.5 & 56.7 & 51.3 & 17.7 & 50.1 & 19.8 \\
\hline $25000-50000$ & 29.7 & 25.7 & 32.5 & 25.2 & 31.6 & 29.8 \\
\hline$>50000$ & 36.8 & 17.7 & 16.2 & 57.1 & 18.3 & 50.5 \\
\hline \multicolumn{7}{|l|}{ Parent education, $\%^{\mathrm{a}}$} \\
\hline Less than high school & 45.8 & 60.3 & 68.2 & 23.9 & 55.5 & 33.2 \\
\hline Some college & 29.2 & 30.2 & 23 & 19.9 & 36.7 & 31.8 \\
\hline Less than college & 25.0 & 9.5 & 8.8 & 56.3 & 7.8 & 35.0 \\
\hline Food insecurity, ${ }^{a}$ & 11.8 & 16.9 & 17.7 & 6.5 & 15.1 & 8.1 \\
\hline Neighborhood safety, $\%^{a}$ & 8.0 & 15.6 & 12.5 & 3.4 & 9.2 & 4.2 \\
\hline \multicolumn{7}{|l|}{ Maternal risk factors } \\
\hline $\mathrm{Wt}, \mathrm{kg}$, mean (SE) ${ }^{\mathrm{a}}$ & $72.2(0.44)$ & $78.76(1.15)$ & $71.10(0.85)$ & $60.46(0.63)$ & $76.02(2.2)$ & $71.30(0.55)$ \\
\hline Smoking during pregnancy, \%a & 9.1 & 6.7 & 4.4 & 0.7 & 19.4 & 13.0 \\
\hline \multicolumn{7}{|l|}{ Infant risk factors } \\
\hline Never breastfed, $\%^{\mathrm{a}}$ & 29.2 & 46.6 & 23.8 & 16.3 & 28.4 & 27.3 \\
\hline Early introduction of solid foods, $\%^{a}$ & 23.7 & 29.8 & 21.2 & 7.5 & 28.6 & 23.9 \\
\hline Wt gain, mean (SE) $)^{a, b}$ & $0.57(0.01)$ & $0.61(0.01)$ & $0.59(0.01)$ & $0.56(0.01)$ & $0.64(0.02)$ & $0.57(0.01)$ \\
\hline \multicolumn{7}{|l|}{ Early childhood risk factors ${ }^{\mathrm{C}}$} \\
\hline Television viewing $>2$ h per d, \%a & 35.6 & 50.6 & 44.8 & 29.4 & 41.6 & 27.5 \\
\hline Physical inactivity, \% ${ }^{\mathrm{a}}$ & 56.1 & 60.4 & 56.8 & 67.8 & 50.8 & 54.1 \\
\hline SSB consumption, $\%^{a}$ & 30.1 & 41.4 & 35.7 & 21.7 & 33.5 & 25.0 \\
\hline $\begin{array}{l}\text { Fruit and vegetable consumption }<1 \text { per } \\
\quad \text { d, } \%\end{array}$ & 18.5 & 20.3 & 16.8 & 16.5 & 19.8 & 19.0 \\
\hline Family meals $<4$ per wk (\%) ${ }^{\mathrm{a}}$ & 16.1 & 24.6 & 20.2 & 16.9 & 16.8 & 11.9 \\
\hline Nonparental child care, $\%^{\mathrm{a}}$ & 80.2 & 84.0 & 73.2 & 84.8 & 79.3 & 82.0 \\
\hline \multicolumn{7}{|l|}{ BMI $z$ score, mean (SE) } \\
\hline \multicolumn{7}{|l|}{ Boys } \\
\hline 2 y $(2003-2004)^{a}$ & $0.52(0.05)$ & $0.58(0.12)$ & $0.66(0.11)$ & $0.28(0.12)$ & $0.73(0.25)$ & $0.44(0.07)$ \\
\hline Preschool (2005-2006) a & $0.67(0.03)$ & $0.65(0.09)$ & $0.86(0.07)$ & $0.44(0.10)$ & $1.04(0.15)$ & $0.59(0.04)$ \\
\hline Kindergarten $(2006)^{\mathrm{a}}$ & $0.69(0.03)$ & $0.75(0.07)$ & $0.93(0.07)$ & $0.48(0.11)$ & $0.93(0.09)$ & $0.58(0.04)$ \\
\hline \multicolumn{7}{|l|}{ Girls } \\
\hline 2 y (2003-2004) & $0.34(0.06)$ & $0.30(0.15)$ & $0.43(0.16)$ & $0.30(0.11)$ & $0.62(0.15)$ & $0.30(0.08)$ \\
\hline Preschool $(2005-06)^{\mathrm{a}}$ & $0.66(0.03)$ & $0.70(0.07)$ & $0.79(0.06)$ & $0.38(0.09)$ & $1.00(0.11)$ & $0.60(0.04)$ \\
\hline Kindergarten (2006) ${ }^{\mathrm{a}}$ & $0.68(0.03)$ & $0.76(0.07)$ & $0.78(0.06)$ & $0.34(0.10)$ & $1.04(0.11)$ & $0.61(0.04)$ \\
\hline \multicolumn{7}{|l|}{ Overweight and/or obesity, \% } \\
\hline \multicolumn{7}{|l|}{ Boys } \\
\hline 2 у (2003-2004) & 17.5 & 17.3 & 20.1 & 12.2 & 27.3 & 16.3 \\
\hline Preschool (2005-2006) & 33.6 & 37.2 & 39.9 & 24.5 & 47.0 & 29.7 \\
\hline Kindergarten $(2006)^{\mathrm{a}}$ & 34.8 & 41.0 & 43.7 & 29.4 & 42.8 & 29.0 \\
\hline \multicolumn{7}{|l|}{ Girls } \\
\hline 2 у (2003-2004) & 16.7 & 16.4 & 17.0 & 14.0 & 22.2 & 16.5 \\
\hline Preschool (2005-2006) a & 34.8 & 36.8 & 42.6 & 28.7 & 47.1 & 30.9 \\
\hline Kindergarten $(2006)^{\mathrm{a}}$ & 35.1 & 39.9 & 39.9 & 29.6 & 49.2 & 31.5 \\
\hline
\end{tabular}

a $P$ value for the difference across races is $<.01$.

${ }^{b}$ Nine-mo rate of infant wt gain $(\mathrm{kg})$ is wt at 9 mo birth wt over age in mo at the first wave of data collection $(\sim 9 \mathrm{mo})$.

${ }^{\mathrm{c}}$ Measured at wave 3 of data collection.

American boys to $104 \%$ among white versus Hispanic girls (Supplemental Materials). A contribution of $>100 \%$ means that Hispanic girls would be even better off than white girls if their SES could be adjusted to levels found among white girls.

Maternal and early childhood risk factors played negligible roles in explaining racial and/or ethnic disparities in BMI $z$ scores. For example, maternal risk factors accounted for $<20 \%$ of the explained gaps between white children and children of other racial and/or ethnic groups, except between white and Asian children, in which they played a more substantial role. On the other hand, the contribution of early childhood risk factors was more evident between white and Hispanic girls.

\section{DISCUSSION}

We examined the distributions of early childhood obesity risk factors by race and/or ethnicity and the extent to which they explained disparities in BMI $z$ scores at 


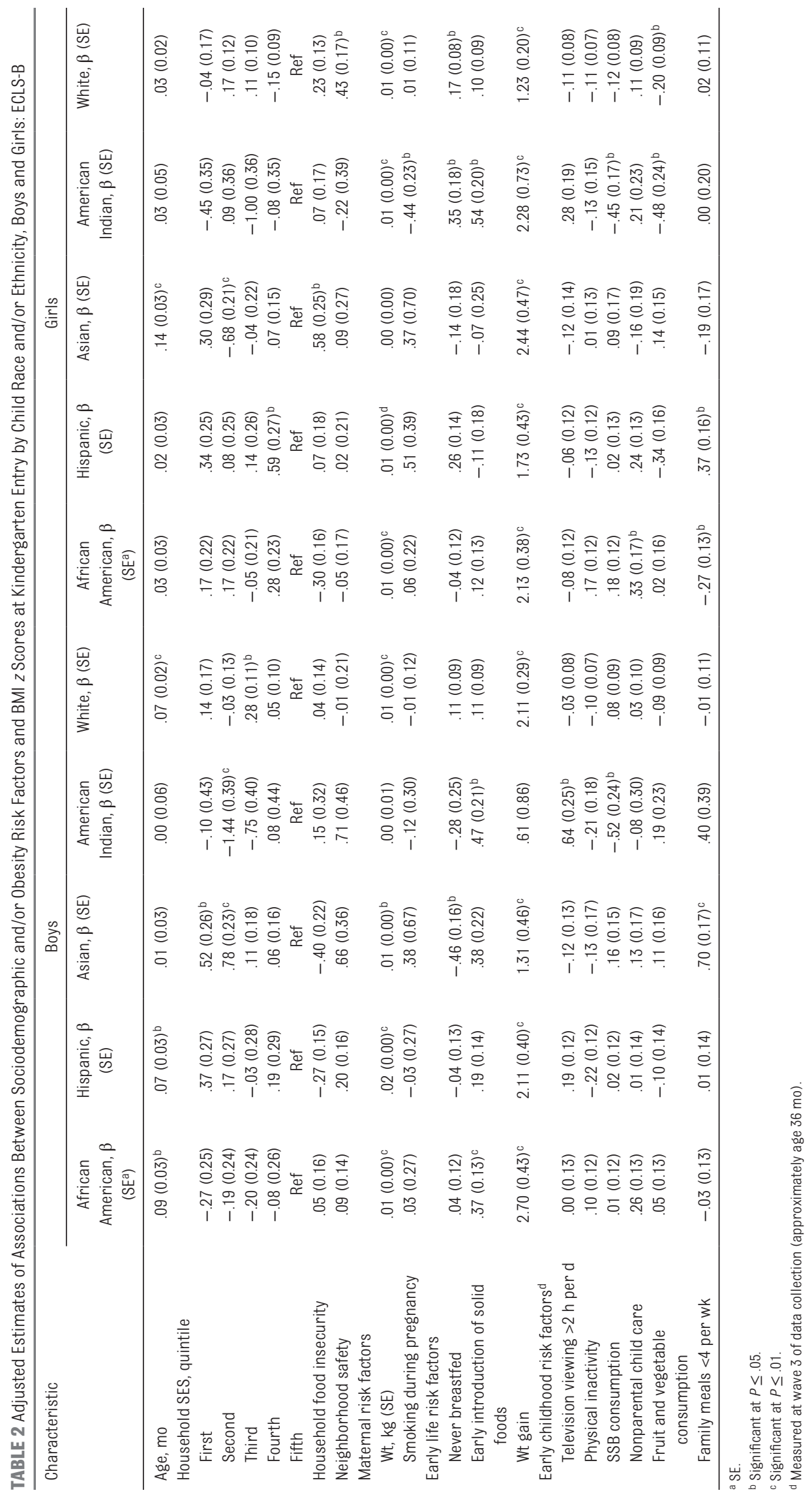




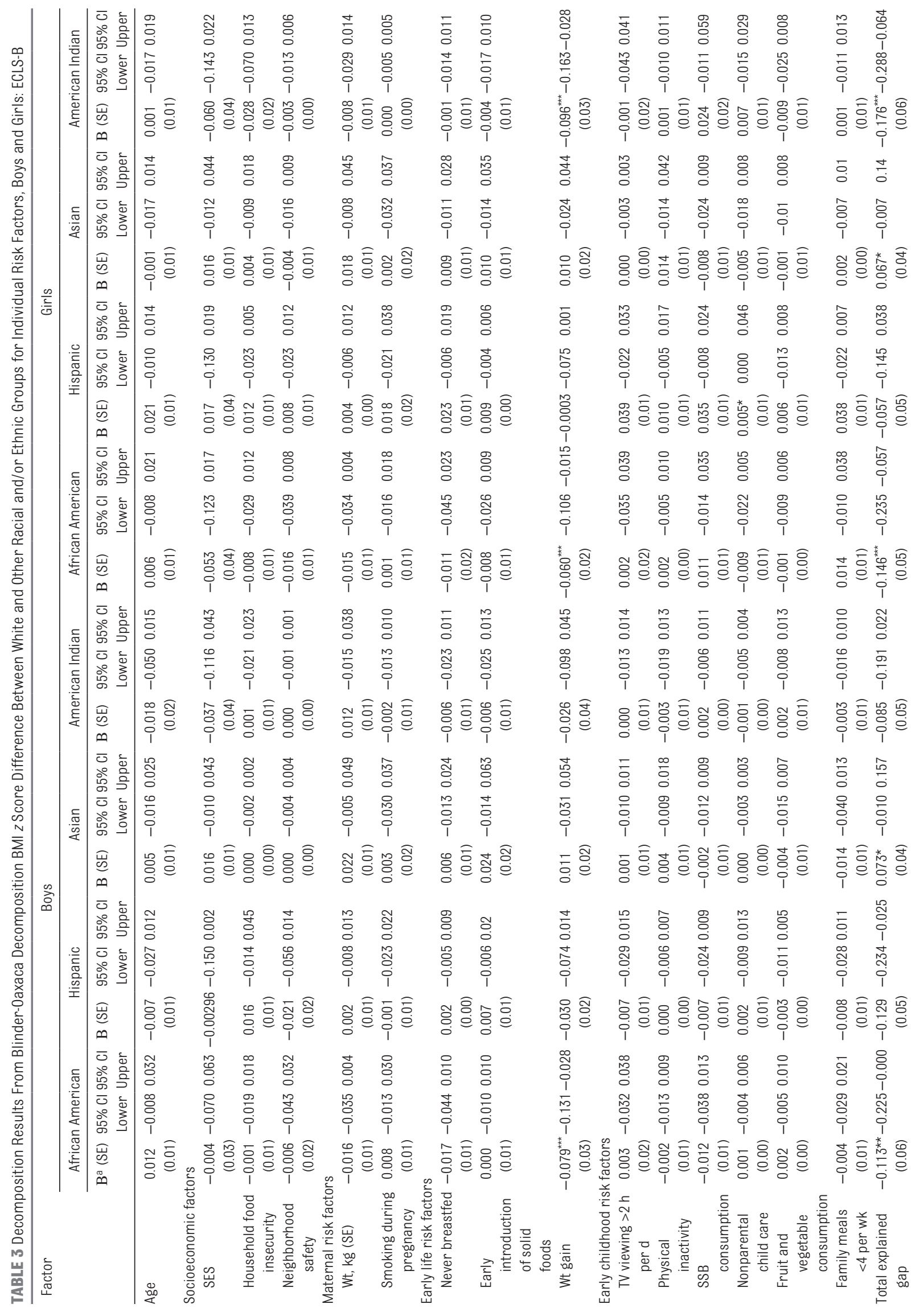




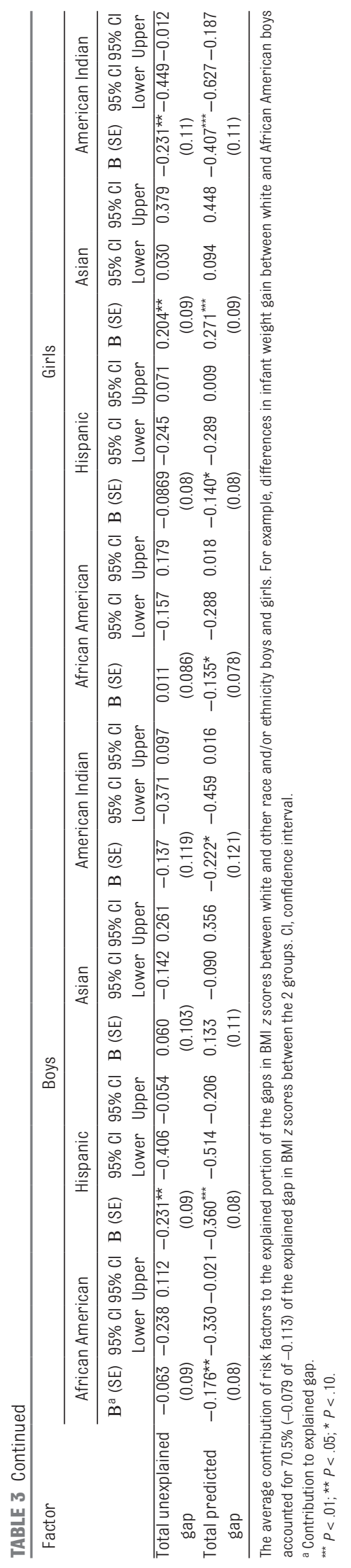

kindergarten entry. We found that other than among Hispanic children, the rate of infant weight gain in the first 9 months of life had the most substantial contribution to explained racial and/or ethnic disparities in early childhood obesity. This finding reflects the fact that infant weight gain was the strongest predictor of children's BMI $z$ scores at kindergarten entry and also varied significantly by race and/or ethnicity. Rapid infant weight gain has been previously shown to be associated with childhood obesity ${ }^{26,27}$ and is thought to be 1 of the primary determinants in the first year of life of later-onset obesity. ${ }^{28}$ Infant weight gain is also known to differ by race and/or ethnicity. ${ }^{8}$ Racial and/or ethnic differences in feeding and childrearing practices ${ }^{29}$ could contribute to observed differences. For example, Ejlerskov et $\mathrm{al}^{27}$ reported that the impact of infant weight gain on later obesity is attenuated by longer breastfeeding duration. This could mean that racial and/or ethnic groups with historically lower rates of breastfeeding 8,30 might not benefit from its protective effect against obesity.

Besides infant weight gain, socioeconomic factors (predominantly SES) were also significant contributors to explained disparities, particularly among Hispanic children. Hispanic children were noted to have a high prevalence of obesity risk factors, but in models that adjusted for socioeconomic factors, their risk factor profile was 1 of the best of all racial and/or ethnic groups and as favorable as that of Asian children. There are welldocumented racial and/or ethnic differences in SES, ${ }^{31}$ and household SES is known to be associated with childhood obesity. ${ }^{32}$ However, because patterns of association between SES and obesity are complex and vary by race and/or ethnicity, age, sex, and over time, ${ }^{33}$ researchers have suggested that interventions should not focus solely on eliminating income disparities but also address other contributory factors. ${ }^{33}$ Neighborhood SES and certain features of the built environment are some potential contributory contextual factors ${ }^{34}$ that could be considered, along with important individual-level factors.

An unexpected finding in this study was that some known behavioral obesity risk factors (eg, fruit and vegetable consumption and television viewing) played a relatively minor role in explaining racial and/or ethnic differences in children's BMI $z$ scores after accounting for other factors. In our study, these risk factors were not significant predictors of BMI $z$ scores at kindergarten entry except among white girls and American Indian children. Guerrero et $\mathrm{al}^{12}$ also documented that television viewing and fruit and vegetable consumption were not predictive of BMI growth for any racial and/or ethnic group. In previous studies, maternal, infancy, and early childhood risk factors collectively fully explained racial and/or ethnic differences in preschool-aged children's weight status. ${ }^{9,10,12}$ There were no African American-white differences in US preschool-aged children's weight status after adjusting for prenatal, perinatal, and early life risk and protective factors. ${ }^{9}$ Taber et $\mathrm{al}^{21}$ assessed the sources of disparities in adolescent obesity prevalence and found that measured behavioral and environmental factors only accounted for $46.8 \%$ of the racial prevalence disparities. Important factors contributing to differences between African American and white girls were more screen time, less fruit and vegetable access at home, less sports participation, and greater probability of obtaining school lunch versus lunch from home. In our study, we found that for most racial and/or ethnic groups, maternal and early childhood risk factors played a 
less important role compared with factors in early infancy. In addition, covariates that contributed to explained disparities differed by race and/or ethnicity. For example, the same factors that accounted for $64 \%$ of the explained disparities between white and African American boys only accounted for $36 \%$ of explained disparities between white and Hispanic boys.

Our study has some limitations. Although the decomposition technique can explore potential mechanisms in more detailed ways than can traditional regression methods, we cannot conclusively attribute causality to the obesity risk factors examined in this study. Although we accounted for a wide array of confounders and risk factors, there is still potential for residual confounding or model misspecification. In addition, the measurement of behavioral risk factors was based on parents' reports, and therefore could have been subject to misreporting or measurement error. This could have resulted in biased estimates that may not fully represent the degree to which these risk factors contribute to explained gaps. Results may also vary depending on how SES is measured. For this reason, it has been recommended that researchers should assess the robustness of their findings by using multiple SES measures. ${ }^{35}$ To minimize this limitation, we used a composite variable for our SES measure that comprised information on both parents' educational attainment, occupation, and household income. Our study sample excluded children who were born with low birth weight because their growth trajectories are typically different from normal birth weight children. We also limited our analytic sample to children of only 5 racial and/or ethnic groups. As part of the decomposition analysis, we relied on a complete case analysis to ensure that each decomposition model included the same sample of children. This resulted in children with missing values on any independent variable being excluded. The degree of missing data could impact the generalizability of our findings and result in biased estimates or a failure to detect a significant effect. The ECLS-B study was conducted on US children born in 2001 and followed for 6 years (through 2007), and therefore, our findings need to be replicated with more recent data. In spite of these limitations, we believe our findings make an important contribution to the field by highlighting the extent to which infancy weight gain contributes to racial and/or ethnic disparities in early childhood obesity. The study provides a more nuanced picture of the role that various groups of obesity risk factors play in explaining racial and/or ethnic disparities in US preschool-aged children's weight status.

Our study has 3 important public health implications. First, if the association between infant weight gain and obesity is causal, then interventions that target determinants of rapid infant weight gain could lead to substantial reductions in observed racial and/or ethnic disparities in childhood obesity. Short breastfeeding duration, formula feeding, and feeding to schedule are some modifiable exposures that have been linked to rapid infant weight gain $^{36,37}$ and can be effective policy or intervention targets. Tailored interventions implemented at birth or in early infancy, such as home visits, group visits, or in-home-based interventions that educate parents on responsive parenting and optimal infant feeding practices, are promising prevention approaches. ${ }^{38-40}$ Second, given that the relative importance of risk factors differed across groups, efforts should be tailored to address the unique contributory risk factors for specific racial and/or ethnic groups. Finally, our findings indicate that policies and programs that target household socioeconomic disadvantage in addition to key contributory factors might be beneficial in preventing early childhood obesity, particularly among Hispanic children. Interventions implemented early in the life course that target these important contributory risk factors may help reduce the magnitude of racial and/or ethnic disparities in early childhood obesity.

\section{CONCLUSIONS}

Differences in rapid infant weight gain contribute substantially to racial and/or ethnic disparities in obesity during early childhood. Interventions implemented early in life to target this risk factor could help curb widening racial and/or ethnic disparities in early childhood obesity.

ABBREVIATIONS
$\begin{aligned} & \text { ECLS-B: } \\ & \text { Early Childhood } \\ & \text { Longitudinal Study Birth } \\ & \text { Cohort }\end{aligned}$
NCES: National Center for
Education Statistics
OLS: ordinary least squares
PE\%: percent explained
SES: socioeconomic status
SSB: sugar-sweetened beverage

Address correspondence to Inyang A. Isong, MD, ScD, MPH, Primary Care at Longwood, Boston Children's Hospital, 300 Longwood Ave, Boston, MA 02115. E-mail: inyang.isong@childrens.harvard.edu

PEDIATRICS (ISSN Numbers: Print, 0031-4005; Online, 1098-4275)

Copyright (C) 2018 by the American Academy of Pediatrics 
FINANCIAL DISCLOSURE: The authors have indicated they have no financial relationships relevant to this article to disclose.

FUNDING: Dr Isong received a stipend during her doctoral program from the Pritzker obesity prevention award. Dr Avendaño is supported by the European Union's Horizon 2020 research and innovation program (grant agreement 633666 [Lifepath]) and the National Institute on Aging (award R01AG040248). Dr Bind was supported by the Bill and Ann Ziff Foundation at the Harvard Center for the Environment and by the Office of the Director of the National Institutes of Health (award DP50D021412). The content is solely the responsibility of the authors and does not necessarily represent the official views of the National Institutes of Health. Funded by the National Institutes of Health (NIH).

POTENTIAL CONFLICT OF INTEREST: The authors have indicated they have no potential conflicts of interest to disclose.

\section{REFERENCES}

1. Anderson SE, Whitaker RC. Prevalence of obesity among US preschool children in different racial and ethnic groups. Arch Pediatr Adolesc Med. 2009;163(4):344-348

2. Campión J, Milagro Fl, Martínez JA. Individuality and epigenetics in obesity. Obes Rev. 2009;10(4):383-392

3. Han JC, Lawlor DA, Kimm SY. Childhood obesity. Lancet. 2010;375(9727):1737-1748

4. Biro FM, Wien M. Childhood obesity and adult morbidities. Am J Clin Nutr. 2010;91(5):1499S-1505S

5. Li L, Peters H, Gama A, et al. Maternal smoking in pregnancy association with childhood adiposity and blood pressure. Pediatr Obes. 2016;11(3):202-209

6. Burdette HL, Whitaker RC, Hall WC, Daniels SR. Breastfeeding, introduction of complementary foods, and adiposity at $5 \mathrm{y}$ of age. Am $\mathrm{J}$ Clin Nutr. 2006;83(3):550-558

7. Katzmarzyk PT, Barreira TV, Broyles ST, et al; ISCOLE Research Group. Relationship between lifestyle behaviors and obesity in children ages 9-11: results from a 12-country study. Obesity (Silver Spring). 2015;23(8):1696-1702

8. Taveras EM, Gillman MW, Kleinman K, Rich-Edwards JW, Rifas-Shiman SL. Racial/ethnic differences in early-life risk factors for childhood obesity. Pediatrics. 2010;125(4):686-695

9. Weden MM, Brownell P, Rendall MS. Prenatal, perinatal, early life, and sociodemographic factors underlying racial differences in the likelihood of high body mass index in early childhood. Am J Public Health. 2012;102 (11):2057-2067

10. Taveras EM, Gillman MW, Kleinman KP, Rich-Edwards JW, Rifas-Shiman
SL. Reducing racial/ethnic disparities in childhood obesity: the role of early life risk factors. JAMA Pediatr. 2013;167(8):731-738

11. Jones-Smith JC, Dieckmann MG, Gottlieb L, Chow J, Fernald LC. Socioeconomic status and trajectory of overweight from birth to midchildhood: the Early Childhood Longitudinal Study Birth Cohort. PLoS One. 2014;9(6):e100181

12. Guerrero AD, Mao C, Fuller B, Bridges M, Franke T, Kuo AA. Racial and ethnic disparities in early childhood obesity: growth trajectories in body mass index. $J$ Racial Ethn Health Disparities. 2016;3(1):129-137

13. National Center for Education Statistics. Early Childhood Longitudinal Program (ECLS), Birth Cohort (ECLS-B). Available at: http://nces.ed.gov/ecls/ birth.asp. Accessed July 3, 2017

14. Centers for Disease Control and Prevention. Growth charts. Available at: http://www.cdc.gov/growthcharts/. Accessed July 3, 2017

15. Oaxaca R. Male-female differentials in urban labor markets. Int Econ Rev. 1973;14:693-709

16. Blinder AS. Wage discrimination: reduced form and structural estimates. J Hum Resour. 1973;8(4):436-455

17. Yoo BK, Hasebe T, Szilagyi PG. Decomposing racial/ethnic disparities in influenza vaccination among the elderly. Vaccine. 2015;33(26): 2997-3002

18. Rao RS, Graubard BI, Breen N, Gastwirth JL. Understanding the factors underlying disparities in cancer screening rates using the Peters-Belson approach: results from the 1998 National Health
Interview Survey. Med Care. 2004;42(8):789-800

19. Sen B, Mennemeyer S, Gary LC. The relationship between perceptions of neighborhood characteristics and obesity among children. In: Grossman M, Mocan N, eds. Economic Aspects of Obesity (National Bureau of Economic Research Conference Report). Chicago, IL: University of Chicago Press: 2011:145-180

20. Sen B. Using the Oaxaca-Blinder decomposition as an empirical tool to analyze racial disparities in obesity. Obesity (Silver Spring). 2014;22(7):1750-1755

21. Taber DR, Robinson WR, Bleich SN, Wang YC. Deconstructing race and gender differences in adolescent obesity: Oaxaca-Blinder decomposition. Obesity (Silver Spring). 2016;24(3):719-726

22. Powell LM, Wada R, Krauss RC, Wang Y Ethnic disparities in adolescent body mass index in the United States: the role of parental socioeconomic status and economic contextual factors. Soc Sci Med. 2012;75(3):469-476

23. Kranjac AW, Wagmiller RL. Association between age and obesity over time. Pediatrics. 2016;137(5):e20152096

24. Jann B. The Blinder-0axaca decomposition for linear regression models. Stata J. 2008;8(4):453-479

25. Ogden CL, Kuczmarski RJ, Flegal KM, et al. Centers for Disease Control and Prevention 2000 growth charts for the United States: improvements to the 1977 National Center for Health Statistics version. Pediatrics 2002;109(1):45-60

26. Baird J, Fisher D, Lucas P, Kleijnen J, Roberts H, Law C. Being big or growing fast: systematic review of size and growth in infancy and later obesity. BMJ. 2005:331(7522):929 
27. Ejlerskov KT, Christensen LB, Ritz C, Jensen SM, Molgaard C, Michaelsen KF. The impact of early growth patterns and infant feeding on body composition at 3 years of age. $\mathrm{Br} \mathrm{J}$ Nutr. 2015;114(2):316-327

28. Dixon B, Peña MM, Taveras EM. Lifecourse approach to racial/ethnic disparities in childhood obesity. Adv Nutr. 2012;3(1):73-82

29. Kumanyika SK. Environmental influences on childhood obesity: ethnic and cultural influences in context. Physiol Behav. 2008;94(1):61-70

30. Scanlon K, Grummer-Strawn L, Li R, Chen J, Molinari N, Perrine C; Centers for Disease Control and Prevention. Racial and ethnic differences in breastfeeding initiation and duration, by state-National Immunization Survey, United States, 2004-2008. MMWR Morb Mortal Wkly Rep. 2010;59(11):327-334

31. Williams DR, Mohammed SA, Leavell J, Collins C. Race, socioeconomic status, and health: complexities, ongoing challenges, and research opportunities. Ann N Y Acad Sci. 2010;1186:69-101
32. Rossen LM, Schoendorf KC. Measuring health disparities: trends in racialethnic and socioeconomic disparities in obesity among 2- to 18-year old youth in the United States, 2001-2010. Ann Epidemiol. 2012;22(10):698-704

33. Wang $Y$, Zhang $Q$. Are American children and adolescents of low socioeconomic status at increased risk of obesity? Changes in the association between overweight and family income between 1971 and 2002. Am J Clin Nutr. 2006;84(4):707-716

34. Sharifi M, Sequist TD, Rifas-Shiman $\mathrm{SL}$, et al. The role of neighborhood characteristics and the built environment in understanding racial/ ethnic disparities in childhood obesity. Prev Med. 2016;91:103-109

35. Braveman P, Cubbin C, Marchi K Egerter S, Chavez G. Measuring socioeconomic status/position in studies of racial/ethnic disparities: maternal and infant health. Public Health Rep. 2001;116(5):449-463

36. Carling SJ, Demment MM, Kjolhede $\mathrm{CL}$, Olson $\mathrm{CM}$. Breastfeeding duration and weight gain trajectory in infancy. Pediatrics. 2015;135(1):111-119
37. Oddy WH, Mori TA, Huang RC, et al. Early infant feeding and adiposity risk: from infancy to adulthood. Ann Nutr Metab. 2014;64 (3-4):262-270

38. Savage JS, Birch LL, Marini M, Anzman-Frasca S, Paul IM. Effect of the INSIGHT responsive parenting intervention on rapid infant weight gain and overweight status at age 1 year: a randomized clinical trial. JAMA Pediatr. 2016;170(8):742-749

39. Daniels LA, Mallan KM, Battistutta D, Nicholson JM, Perry R, Magarey A. Evaluation of an intervention to promote protective infant feeding practices to prevent childhood obesity: outcomes of the NOURISH RCT at 14 months of age and 6 months post the first of two intervention modules. Int J Obes. 2012;36(10):1292-1298

40. Wen LM, Baur LA, Simpson JM, Rissel C, Wardle K, Flood VM. Effectiveness of home based early intervention on children's BMI at age 2: randomised controlled trial [published correction appears in BMJ. 2013;346:f1650. BMJ. 2012;344:e3732 